\title{
Coleção Revoada: Joias comerciais inspiradas nos Pássaros Juninos de Belém-Pa
}

\author{
Collection Revoada: Commercial jewelry inspired in the Pássaros Juninos of Belém-Pa
}

FERREIRA, José Leuan Monteiro; Bacharel; Universidade do Estado do Pará

leuanferreira@gmail.com

PINTO, Rosângela Gouvêa; Mestre; Universidade do Estado do Pará

rogouveapinto@gmail.com

\section{Resumo}

Este artigo apresenta o desenvolvimento criativo de uma Coleção de Joias comerciais inspiradas no evento anual dos Pássaros Juninos e outros Bichos a partir de suas referências visuais e conceituais. Esta coleção, intitulada como "Revoada", foi definida para representar a cultura popular destes grupos, sendo concebida através de etapas, onde primeiramente buscou a compreensão sobre a área do Design de Joias, sobre Cultura Popular e sobre os Pássaros Juninos, de modo a utilizar essas informações para a concepção da coleção para posteriormente partir para o processo de geração de ideias e por fim chegar ao resultado de uma exposição. Este projeto visa, a partir desta coleção, relacionar esses assuntos, assim como explicar um pouco mais sobre essa cultura popular que são os grupos de pássaros juninos e outros bichos, de modo que possam ser valorizados e representados através das joias.

Palavras Chave: Joias; Cultura; Pássaros Juninos.

\begin{abstract}
This paper presents the creative development of a Commercial Jewelry Collection inspired by the annual event of the Pássaros Juninos e outros Bicho from their visual and conceptual references. This collection, titled "Revoada", was defined to represent the popular culture of these groups, being conceived through stages, where first it sought the understanding on the area of the Jewelry Design, on Popular Culture and on the Pássaros Juninos, in order to use this information for the design of the collection and then proceed to the process of generating ideas and finally arriving at the result of an exhibition. This Project, starting from this collection, aims to relate these subjects, as well as to explain a little more about this popular culture that are the groups of Pássaros Juninos e outros bichos, so that they can be valued and represented through the jewels.
\end{abstract}

Keywords: Jewels; Culture; Pássaros Juninos. 


\section{Introdução}

O objeto de pesquisa e estudo deste trabalho é a cultura dos pássaros juninos, oriundos da cidade de Belém do Estado do Pará, que são grupos de teatro popular que apresentam peças teatrais anualmente no período do mês de junho e que são escritas pelos guardiões ${ }^{1}$ de cada grupo. O despertar do interesse em estudar esta cultura popular parte de uma memória afetiva de infância, quando a ida para presenciar as apresentações teatrais desses grupos juninos nas praças públicas foi proporcionada pelos pais, como forma de ensinar sobre as manifestações da cultura local.

Ainda a estética dos figurinos dos atores, conhecidos como brincantes ${ }^{2}$, provocava fascínio; além das histórias contadas, durante as apresentações, que, certamente incitavam a imaginação dos espectadores que sempre muito atentos seguiam os personagens com olhares curiosos; assim também se dava com o pesquisador, cuja cabeça, ainda pueril, viajava em um cenário mágico e fantasioso, embebido nas ilusões criadas pela performance e enredo dos grupos.

Os grupos dos pássaros passaram e passam por muitas dificuldades ao longo do seu tempo de existência, dentre as quais, os investimentos na cultura que se tornaram um dos grandes problemas para a permanência e manutenção da atividade desta manifestação folclórica junina, dentre outros fatores particulares de cada grupo, acarretando no fim de alguns ou em apresentações não consecutivas anualmente.

Observando essa questão, a pesquisa apresenta como foco, a valorização dos pássaros juninos originais de Belém, através da criação de uma coleção de joias comerciais, inspiradas na estética encontrada nos grupos de pássaros juninos. Entende-se que dessa maneira estará contribuindo para o revigoramento desses grupos e para a possibilidade das novas gerações adquirirem conhecimento e valorizarem esta cultura local, o que permitirá que esse "teatro popular" em Belém tenha reconhecimento, assim fortalecendo sua importância no cenário da cultura local.

Observou-se que os pássaros começaram a perder destaque, tornando-se menos valorizados e em acentuado esquecimento; o que provocou uma queda dos investimentos neste nicho cultural, implicando diretamente na manutenção desses grupos. A partir disso se estabeleceu, como hipótese, que a criação de joias comerciais como elementos de representatividade de uma das vertentes artístico-sociais, proporcionaria maior valorização e difusão dessa manifestação da cultura popular, enfatizando a função estética dos Pássaros Juninos, como fonte de inspiração para sua criação.

Vale ressaltar que esta pesquisa foi oriunda do Trabalho de Conclusão de Curso da UEPA, com resultado do projeto da coleção de joias que foi contemplado no Edital Prêmio de Produção e Difusão Artística em 2017, pelo Projeto SEIVA da Fundação Cultural do Pará, ficando em exposição no Espaço São José Liberto, o que facilitou a validação da hipótese deste trabalho, pois a coleção encontra-se em comercialização no espaço.

Para esta pesquisa, sentiu-se a necessidade de estudar e compreender alguns conceitos relevantes para que pudesse apresentar a coleção de joias como resultado da pesquisa de forma coesa e coerente, portanto, apresenta-se neste artigo conceitos acerca de cultura popular e sobre a cultura dos pássaros juninos, além de expor a metodologia aplicada para o desenvolvimento do

\footnotetext{
${ }^{1}$ Responsáveis e protetores de seus grupos em específico

${ }^{2}$ Nome dado, pelo meio, aos participantes que se apresentam no palco
} 
projeto.

\title{
2 Design e Cultura Popular
}

O termo cultura não possui um conceito estanque, pois está relacionado diretamente com o meio em que se deseja aplicar, no caso deste trabalho, aplicou-se na relação entre cultura e design da qual podemos ver como exemplo as peças da joalheria paraense, já que são peças compostas com materiais alternativos (sementes, madeira, cascas, fibras, etc.), também são beneficiados através de processos tradicionais de artesanato local, além de abordarem temáticas regionais, bem exemplificado nas coleções feitas pelos designers do Pará.

\begin{abstract}
Na busca da representação da cultura local, os designers do Pará alcançam um alto nível de elaboração simbólica em suas criações [...] O diferencial da joalheria do Pará está em seu forte conteúdo simbólico de representação dos traços culturais locais, cuja identidade transparece em cada peça apresentada. Seu caminho está sendo traçado na direção de uma linguagem mais contemporânea e universal, para que a beleza e a magia de seus ícones possam conquistar novos admiradores. (Associação São José Liberto, 2004, p.9).
\end{abstract}

Assim como a história de povos, o conceito de cultura ultrapassa os tempos, pois cultura está interligada diretamente ao cotidiano social, encontrando-se em suas ações, hábitos e costumes, mas de modo resumido. De acordo com Coelho (2008), cultura é vista de um modo geral, possuindo dois significados, sendo o primeiro relacionado com a educação, formação, ilustração do homem e o segundo, com característica sociológica e antropológica, vinculado as manifestações de um povo, de uma raça, de um grupo social.

\begin{abstract}
A compreensão da cultura como manifestação da atividade social é derivada da Teória Crítica, que engloba toda a produção humana, seja ela científica, artística, política ou de qualquer outra natureza, como parte do processo de aperfeiçoamento da práxis social, ou seja, a civilização entendida enquanto correspondência às necessidades fundamentais da sociedade. (COELHO, 2008, p.61).
\end{abstract}

A relação Cultura-Design pode ser observada, de acordo com Coelho (2008) de modo empírico, pois Design é uma atividade onde se configura objetos de uso e, portanto, utiliza de parte dos valores culturais que os envolve, ou seja, grande parte dos objetos de nosso cotidiano, é a materialização dos ideais e das incoerências de nossas sociedades e de suas manifestações culturais. "A figura dos objetos de nosso cotidiano é resultante direta ou indireta do contexto cultural que nos cerca, e esse contexto é cada vez mais complexo e multifacetado". (COELHO, 2008, p.62).

\subsection{Cultura Popular}

A definição de cultura popular é tão complexa de se expor quanto a de cultura em si, pois são termos que acabam por completar uma vastidão de sentidos e entendimentos sobre os seus verdadeiros significados, mas, entre tantos, um autor buscou compreender cultura popular em seis aspectos, Storey (2015) afirma que todos esses conceitos distintos de cultura popular conversam entre si e de modos diferentes. Ele apresenta seis definições que configuram o estudo sobre cultura popular, conforme exposto na figura 1. Mas vale ressaltar que esses conceitos não se apresentam nem conceituam sozinhos, é necessário o conjunto para a compreensão total de cultura popular, ou seja, os significados se complementam e não se subtraem. 
Figura 1 - Significados de Cultura Popular

\begin{tabular}{|c|c|}
\hline $\begin{array}{c}\text { Cultura que possui } \\
\text { ampla apreciação por } \\
\text { muitas pessoas }\end{array}$ & $\begin{array}{c}\text { O que não é } \\
\text { considerado como } \\
\text { alta cultura }\end{array}$ \\
\hline $\begin{array}{c}\text { Cultura em massa } \\
\text { visando o comercial, } \\
\text { o consumo }\end{array}$ & $\begin{array}{c}\text { Ambiente para luta e } \\
\text { resistência de grupos } \\
\text { subordinados }\end{array}$ \\
\hline $\begin{array}{c}\text { Uma cultura pós- } \\
\text { moderna, sem } \\
\text { diferença entre } \\
\text { cultura popular e a } \\
\text { alta cultura }\end{array}$ & $\begin{array}{c}\text { Cultura originada do } \\
\text { "povo" }\end{array}$ \\
\hline
\end{tabular}

Fonte: Autor (2016)

Como dito anteriormente, cada conceito apresentado por Storey (2015) define de modo distinto, mas de modo complementar, estes conceitos se relacionam, como por exemplo, após fazer um recorte na cultura paraense, podemos observar essa conceituação dentro da cultura dos Pássaros Juninos, onde cada item se faz presente e com a afirmação de que estes grupos teatrais são considerados como cultura popular.

Apesar da pouca visibilidade que os grupos de pássaros juninos possuem atualmente, ainda há muitas pessoas que apreciam as peças teatrais, nos períodos de apresentações, os grupos movem centenas de pessoas para presenciarem os enredos mágicos e atemporais contados pelos brincantes. Muitas pessoas assemelham estas peças teatrais a uma ópera, pois as peças contam uma história e possui brincantes representando e cantando, mas como essa manifestação cultural se origina na periferia e por pessoas que muitas vezes não possuem conhecimentos técnicos e estruturais sobre o teatro, estes grupos, então, não são vistos da mesma forma como uma ópera, ficando evidente aquela diferença de cultura popular para alta cultura.

A única característica a não denominar os pássaros juninos seria a cultura relacionada ao comercial e consumo, já que esses grupos realizam suas apresentações gratuitamente e com renda originária de investimento cultural do município de Belém.

\subsection{Grupos de Pássaros Juninos}

O pássaro junino é originário do Pará, mais especificamente de Belém. Considera-se que ele pode ser visto como uma contribuição da cultura local para a cultura nacional no que se refere às festas típicas do mês de junho. De acordo com Charone (2010), há indícios de estruturação do pássaro desde o século XIX, conhecido como um teatro popular e, também, como "Ópera Cabocla", pois as pessoas que participam do grupo e atuam durante as apresentações, como dito anteriormente, são, em grande maioria, moradores da periferia.

Existem dois tipos de grupos de pássaros, um que possui uma característica mais rural, conhecido como Cordão de Pássaro e outro mais urbano, chamado de Pássaro Melodrama Fantasia. (MAUES, 2009). A diferença entre os dois está no modo como eles se apresentam, discussão esta que será enfatizada ao longo destes sub tópicos.

\subsubsection{Histórico dos Pássaros Juninos}


Há indícios de que os primeiros cordões de bicho ${ }^{3}$ datam o ano de 1848, século XIX, quando se apresentavam no Pavilhão da Flora, um edifício em madeira, construído no Largo da Nazaré, para que ocorressem as apresentações de danças e de grupos folclóricos, mas também há registros que identificam os pássaros juninos no ano de 1901, conhecido como "Coruja Real". (SALLES, 1994 apud REFKALEFSKY, 2001).

De acordo com Refkalefsky (2001), essas atuações permitiram que os pássaros tomassem a posição de teatro popular e recebendo espaço para se apresentarem em cinemas e teatros ou até parques, estes que eram cedidos pela municipalidade, fato que ocorre até os dias atuais.

O cordão de pássaros é considerado como uma variante e é encontrado nas zonas urbanas e rurais, mas o pássaro melodrama é um fenômeno urbano, originado a partir das influências pelas óperas e operetas que eram apresentadas no Teatro de Nossa Senhora da Paz, o atualmente Teatro da Paz, permitindo assim, incorporar em sua estrutura dramática elementos de palco, como cortina, iluminação, etc, com adaptações aos recursos artísticos disponíveis e ao gosto popular. (REFKALEFSKY, 2001).

Por essa inspiração nas óperas e operetas que Charone (2010) classifica o Pássaro Melodrama como uma "ópera cabocla", sendo um "[...] fenômeno urbano, com raízes bem fincadas na cultura popular amazônica, de onde tira o substancial de sua inspiração". (CHARONE, 2010, p. 121).

\subsubsection{Teatralidade dos Pássaros}

A realização das peças teatrais em diferentes espaços já é algo comum para todos os grupos de pássaros, pois eles não estabelecem um lugar padrão para as suas apresentações (a não ser no período junino, quando é cedido o Teatro Margarida Schivasappa, CENTUR, em Belém-Pa para as apresentações), logo o espaço teatral dos pássaros, se apresenta sob inúmeras configurações físicas, já que cada espaço tem suas diferenças, daí a necessidade de adaptações, porque "[...] estabelecer uma relação específica com a plateia e os trabalhos de caracterização visual de atores são instrumentos fundamentais nesse diálogo." (RAMOS, 2013, p. 52).

Algo interessante a ser destacado para os grupos de pássaros juninos são os espaços de atuação, ou espaços cênicos, que corresponde à área física que é destinada para a apresentação da peça. Deve ser um espaço concreto e de forte visualidade para os espectadores. Mas muitas vezes estes espaços não possuem os devidos acessórios de cenografia que irão compor as cenas dos personagens, objetos conhecidos como recursos cenotécnicos. (REFKALEFSKY, 2001).

Podemos observar na foto a seguir um teatro com um cenário fixo e único para todos os grupos que ali se apresentarem, o que fortifica que há poucos acessórios de cenografia ou quase nenhum e o que existe, é compartilhado a todos, menos os figurinos, que são realizados individualmente pelos grupos, mas pelo sentimento de colaboração e união entre os grupos, muito desses figurinos são emprestados entre si, menos o figurino pertencente ao pássaro que representa o grupo.

\footnotetext{
${ }^{3}$ Espécie de cortejo onde se utilizavam costumes de animais e que apresentavam número de dança durantes as épocas de festas populares, no Pavilhão da Flora. (Refkalefsky, 2001).
} 
Figura 2 - Espaço Cênico dos Grupos de Pássaros

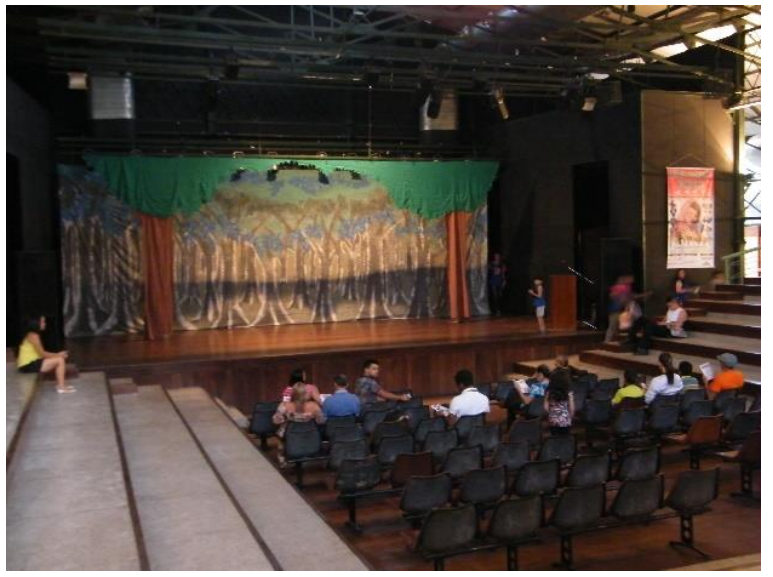

Fonte: Autor (2016)

\subsubsection{Figurinos e Personagens}

Os personagens entre os pássaros melodramas e os cordões de pássaros se diversificam e se transformam e até dentro dos próprios grupos, variando quantidade e tipo de personagens.

[...] constatamos que eles podem transitar livremente nessas modalidades porque elas mantêm as mesmas características psicológicas, as mesmas funções independentemente de estarem relacionados a peças de coronel ou da nobreza e que a materialização de suas características se estabelece, através do figurino teatral. (REFKALEFSKY, 2001, p.86).

Sobre os figurinos dos personagens, é importante detalhar que cada grupo possui características únicas para que haja uma identificação dos personagens, ou seja, o vestuário é um elemento importante de caracterização, como é o caso do pássaro que é o personagem principal.

Os pássaros são os personagens que dão os nomes aos grupos. O figurino elaborado para os bichos da Amazônia é o mais elaborado dentre todos os demais do vestuário presente na peça teatral, sendo todo trabalhado manualmente. Na figura 3 podemos observar alguns figurinos dos pássaros de diferentes grupos, observando também o empenho dos guardiões para que os figurinos possam se diferenciar e ainda continuar caracterizando o seu grupo em específico.

Figura 3 - Pássaros Juninos

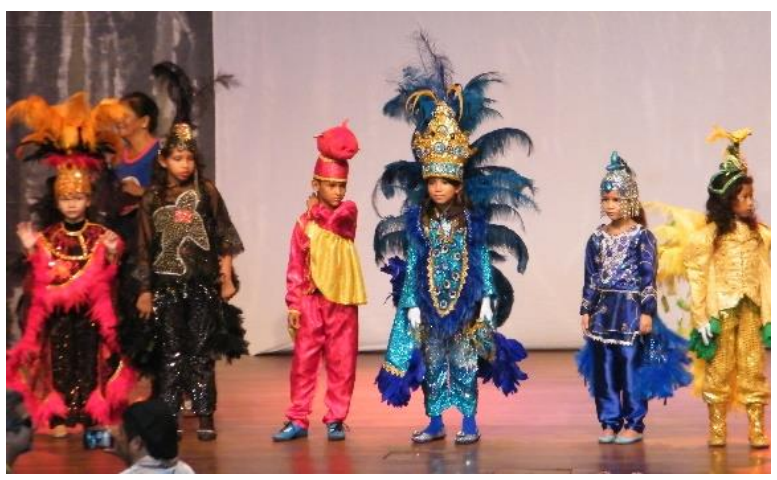

Fonte: Autor (2016) 


\section{Design para Valorização}

O design é um item importante na vida da sociedade, pois ele é compreendido como um elemento básico para o que é ser humano e muito importante quando se trata da qualidade de vida das pessoas, podendo afetar uma sociedade por inteira em todos os aspectos de tudo que as pessoas fazem durante sua rotina. (HESKETT, 2008) O design também é um elemento essencial quando deseja que o objeto transmita algo, seja uma ideia e até um sentimento.

Muitos produtos projetados por designers trazem consigo essa característica de transmissão de valores. Essa função de canal de comunicação está perfeitamente materializada no ramo da criação e produção de joias, atividade na qual o projetista consegue agregar ao produto características únicas e encantadoras que tornam os consumidores afeiçoados às peças de luxo e ao mesmo tempo em interação com a realidade cultural e social.

Santos (2013) afirma que a joia, ao longo da história, sempre foi um objeto de expressão da arte, considerando a arte como uma expressão onde se pode demonstrar as emoções e pensamentos. Apesar de o seu papel principal ter o objetivo de adornar, este ornamento consegue trazer diversos valores, difundindo histórias e momentos.

Dentre esta visão de Santos (2013), podemos nos atentar a joalheria paraense, que carrega em suas peças essas características fortemente através dos materiais alternativos (madeira, fibras, etc.) e das temáticas utilizadas (comumente voltadas à realidade amazônica), sendo isso um padrão presente nas joias paraense, utilizando-se de elementos amazônicos com a intenção de enriquecer o trabalho. Pinto (2012) confirma que a inserção dessa temática regional e local na joia se consolidou no Pará e conta fortemente com uma produção joalheira considerável, em decorrência dos incentivos através de projetos de qualificação e eventos.

\subsection{Metodologia de Projeto}

Para todo o projeto é necessário que haja uma metodologia projetual a ser seguida, portanto, para este trabalho, duas metodologias foram unidas para que o resultado ficasse adequado ao que se é proposto. Os métodos utilizados partiram de Baxter (2011) mesclando com a metodologia apresentada por Gola (2008) e algumas ferramentas de criatividade que ajudaram a dar embasamento suficientes para concretizar o que foi projetado.

Este projeto se estabeleceu em quatro etapas: i) Coleta de Informações; ii) Análise de informações coletadas; iii) Geração de ideias; iv) Detalhamento do produto. Em cada fase estabelecida foram utilizados métodos e técnicas distintas para alcançar os objetivos propostos em cada etapa.

A fase de coleta de informações se deu por toda a etapa de pesquisa e norteamento para o projeto, nestas coletas foram interpretadas características essenciais às joias e feita a imersão e a compreensão do conceito da cultura dos pássaros juninos, que é o enfoque desta pesquisa, toda esta etapa se estabeleceu, principalmente, com pesquisa bibliográfica, entrevistas com membros dos grupos de teatro e participação nos grupos. Então, seguiu-se para a segunda etapa, em que as informações coletadas foram sistematizadas, dando vitalidade a grande parte do projeto.

Foi na segunda fase em que se deu a definição do problema do projeto, observando que o mercado de joias local utiliza de referências culturais com bastante desgaste, mantendo o foco sempre em temáticas já exploradas, condicionando a pouca inovação de temas, portanto esta 
coleção estabelecida a partir de Os Pássaros Juninos se posiciona como inovadora, tendo por intuito despertar uma demanda existente no mercado local ou até mesmo no nacional que requer retratar assuntos novos e com característica distinta das demais peças de joias, possibilitando também a visibilidade necessária para os grupos de pássaros juninos por intermédio das joias.

Posteriormente ao problema de projeto, na segunda fase, definiu-se o público alvo através de duas ferramentas: Persona e Painel Semântico do Público-Alvo, apresentadas por Pazmino (2015). Sendo este item de fundamental importância para dar prosseguimento ao trabalho, já que é neste elemento que começa a se definir o estilo a ser seguido na estética dos produtos. A opção por estas duas ferramentas visa a simplificação na compreensão e estruturação do público.

Outro ponto importante é a análise de similares, em que se utilizou mais uma ferramenta, de acordo com Pazmino (2015), para facilitar o processo: análise sincrônica ou paramétrica. Esta técnica tem a intenção de comparar os produtos em aspectos quantitativos e qualitativos, permitindo identificar elementos e cores pertinentes a serem expostas no resultado. Como terceira etapa temos a definição do estilo, é neste momento que se dá a conclusão de materiais, formas, cores a serem utilizados.

Utilizando da ferramenta de definição do simbolismo de produto do Baxter (2011), selecionou três palavras-chaves que simplificam o conceito da coleção de joias e com as quais foram montados painéis, um para cada palavra, que mostrassem através de figuras a emoção e expressão do produto: a) história; b) místico; c) fulgor. Cada uma dessas palavras representa uma característica presente nos grupos, indo da tradição até aos figurinos. E juntamente com esses painéis, utilizou-se o caderno de inspirações e tendências Outono-Inverno 2017 (SENAI, 2016) para embasar e contribuir com o processo.

Na figura 4 podemos conferir o painel de estilo das peças dos Pássaros Juninos.

Figura 4 - Painel de Estilo Pássaro Junino

\begin{tabular}{|ll|}
\hline \multicolumn{3}{|c|}{ PÁSSARO JUNINO } \\
MATERIAIS & GEMAS \\
1. METAL & 1. GRANADA \\
2. CORRENTES FINASE DELICADAS & 2. CITRINO \\
3. INCRUSTACÃO PARAENSE & 3. TOPAZZIO IMPERIAL \\
4. MADREPEROLA & 4. BERILO \\
5. MADEIRA & 5. OUARTZO RÓSEO \\
6. RESINA & 6. GREENGOLD \\
& \\
ACABAMENTOS & ESTÉTICA \\
1. BRILHO & 1. VISUAL LEVE SOFISTCADO \\
& 2. ASSTMETRIA \\
& 3. VOLUME SUTL \\
4. FORMAS LIMPAS \\
\\
\end{tabular}

Fonte: Autor (2016)

Após a definição do estilo, é necessário fazer uma seleção do que foi definido até o momento para que o projeto fique focado e direcionado da melhor forma, ou seja, é neste momento que 
ocorre um filtro de todas as ferramentas até aqui utilizadas, portanto, este processo ocorreu com base na definição dos requisitos de projeto, que serviu para definição de metas que devessem ser atingidas e classificando em obrigatórias ou não a partir das funções de projeto (Prática, Estética e Simbólica). Esta ferramenta é de grande importância para orientação do processo e dando prosseguimento para a terceira fase, a de geração de ideias.

Na fase de geração de ideias é o momento da utilização de toda a criatividade para realizar diversas alternativas para atingir o objetivo final do projeto, neste momento, também ainda se utiliza de ferramentas de criatividade, como ocorreu neste trabalho, em que utilizou da técnica do mapa conceitual procurando estruturar visualmente o pensamento criativo o que permite um olhar panorâmico do problema e um planejamento corretos dos objetivos, além de ser uma técnica que consiste em reunir uma grande quantidade de informações acerca do projeto em um só lugar.

Essa estruturação visual do projeto, permitiu o direcionamento do processo de criação e o início de diversos esboços, mas, especificamente, para os desenhos, também se utilizou de técnicas, conforme as apresentadas por Wong (2001), nas quais são apresentados métodos que compreendem repetição, inversão, etc os quais proporcionam facilitação para reposicionar as formas e permitir o olhar em diferentes direções, permitindo que o processo criativo se expanda, gerando muito mais esboços e aumentando as chances de atingir o resultado almejado com o projeto. Com todos os esboços prontos, foi realizado a seleção desses projetos observando os requisitos de projeto estabelecidos anteriormente e com esta triagem dos desenhos, conseguiu dividir os projetos em três grupos, especificamente, em três linhas que irão compor a coleção.

Selecionadas essas três linhas, pode-se definir o conceito da coleção, juntamente com seu nome. Assim a coleção fora identificada como "Revoada"; o que se justifica pelo fato de haver um momento dentro do período festivo junino no município, considerado a abertura do arraial de todos os santos, em que todos os grupos de pássaros se reúnem e saem pelas ruas da cidade de um ponto pré-definido pelos pássaros juninos até o local em que será realizado a abertura do arraial. Esta celebração é conhecida como "Revoada", ou seja, os pássaros juninos tomam as ruas e saem fazendo festa em comemoração ao início da festividade.

As três linhas da coleção são: a) Nobreza; b) Pássaros; c) Guardião. A linha Nobreza apresenta peças dentro de um conceito que retrata a busca pelo pássaro, assim como elege este personagem como símbolo de proteção. Nesta linha encontramos elementos com formas curvas, com presença de arabescos, círculos etc., constituem-se nos principais ícones desta linha.

$\mathrm{Na}$ linha Pássaros, encontramos peças que representam alguns grupos de pássaros melodramas e de cordões de pássaros e outros bichos, além de remeter a abertura do arraial, onde possuem três peças com o mesmo nome da coleção, as peças também possuem elementos menores e figurativos de alguns personagens dentro dos enredos.

Por fim, a linha Guardião apresenta peças retratando a natureza, joias com flores, folhas, nas quais buscou-se dar um maior brilho, por intermédio de gemas e do próprio metal. Esta linha tem seu conceito baseado na proteção da natureza, proporcionando uma relação com o guardião do grupo do pássaro, ou seja, a natureza serve dentro da peça como um guia para os personagens e uma proteção para eles; assim como mantem a ideia de preservação do meio ambiente. Aqui encontramos joias com formas suaves e cores amenas, somando a isso elementos decorativos de folhas e flores. 
Finalmente, na quarta fase do projeto é apresentado o desenho técnico de todos os projetos selecionados, reunidos em 32 conjuntos (32 Brincos, 32 Pingentes/Colares, 30 Anéis e 2 Pulseiras, totalizando 96 peças de Prata e Ouro com Gemas Orgânicas), mas para o trabalho de conclusão de curso foi selecionado um projeto para fabricação, o Pássaro Protetor, esta peça faz parte da linha nobreza.

\section{Resultados}

\subsection{Trabalho de Conclusão de Curso}

A fabricação do conjunto selecionado foi uma etapa terceirizada, sendo feita por um profissional da ourivesaria, Ednaldo Pereira. A fabricação da peça foi acompanhada de perto, incluindo a observação de algumas etapas da fabricação, como: corte da chapa, soldagem, incrustação paraense e polimento.

O corte da chapa e soldagem é a etapa inicial para dar forma as peças, para o qual se utilizam ferramentas específicas da bancada do ourives, como o arco de serra e o maçarico e este momento inicial foi realizado pelo ourives, que após a montagem das peças, deixou-lhes um vão para receberem as cores necessárias. Esta etapa de acrescentar cor às peças é realizada pelo autor, cuja técnica foi desenvolvida localmente para agregar coloração adequada às peças; sendo similar ao processo de esmaltação, mas com diferenças do material utilizado, podendo se fazer uso até mesmo de material natural para colorir (ABRAHIM, 2007). Esta técnica é conhecida como Incrustação Paraense, sendo nomeada e estudada pela designer Lídia Abrahim. É esta técnica que acrescenta o diferencial da coleção de joias, pois passa a ter a policromia representando assim todas as cores de todos os grupos.

Após a tarefa de incrustação, o ourives realiza o polimento das peças para que o material incrustado ganhe um maior brilho, assim como o metal, tendo o seu resultado conferido na figura 5. Nesta figura, pode-se observar como é importante a metodologia do projeto, pois possibilita reconhecer nessas imagens que há nas joias a presença de gemas (Granada), da Incrustação Paraense, do metal e de correntes delicadas; o que segue o estilo definido ao longo do projeto, além de que as cores presentes são as mesmas cores do grupo do Pássaro Junino Uirapuru (Laranja e Preto), além de fazer referência direta à parte do enredo teatral em que se apresenta o personagem principal (o pássaro) como um protetor e guardião de outros personagens que necessitam de ajuda. Esta foi a única peça produzida para o Trabalho de Conclusão de Curso, todavia houve a oportunidade, por intermédio da seleção em um concurso da Fundação Cultural do Pará, da confecção de toda a coleção e de sua exposição realizada pelo Edital SEIVA.

Figura 5 - Conjunto Pássaro Protetor

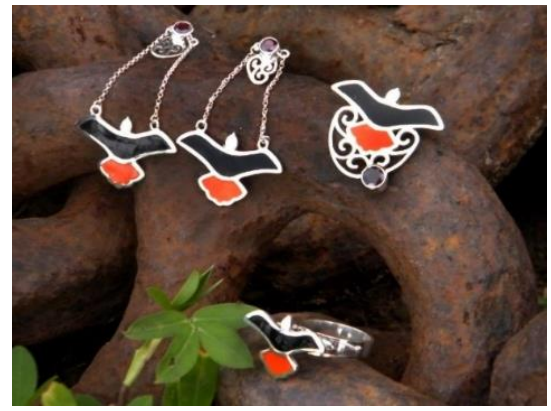

Fonte: Autor (2016) 


\subsection{Exposição da Coleção Revoada}

A coleção de joias, nomeada como Revoada, no ano de 2017, foi contemplada no Edital SEIVA no Prêmio de Produção e Difusão Artística 2017 da Fundação Cultural do Pará. Este prêmio, possibilitou a fabricação de todas as peças e além de resultar em uma exposição realizada no Espaço São José Liberto ${ }^{4}$, através do Programa Polo Joalheiro.

Para a realização da exposição, foi feita a curadoria das peças fabricadas que ficou a cargo da professora Msca - Rosângela Gouvêa Pinto, a qual já havia participado da projeção desta coleção como orientadora do processo do Trabalho de Conclusão de Curso. A confecção das joias foi executada pelo ourives Ednaldo Pereira.

Posteriormente à curadoria da coleção, foi realizado um editorial fotográfico com duas modelos, Taís Carneiro e Brenda Paes, com direção criativa do autor e fotografia de Breno Nonato. As fotos tinham como objetivo apresentar as joias e suas formas de uso. Também as fotos se fizeram úteis como mecanismo de chamadas e publicidade para a abertura da exposição e de sua totalidade. $\mathrm{Na}$ figura 6, podem ser observadas algumas imagens provenientes do editorial fotográfico realizado, aparecendo, à esquerda, o conjunto Pequeno Guará com a modelo Brenda Paes e, à direita, o conjunto Revoada III, com a modelo Taís Carneiro.

Figura 6 - Editorial Fotográfico

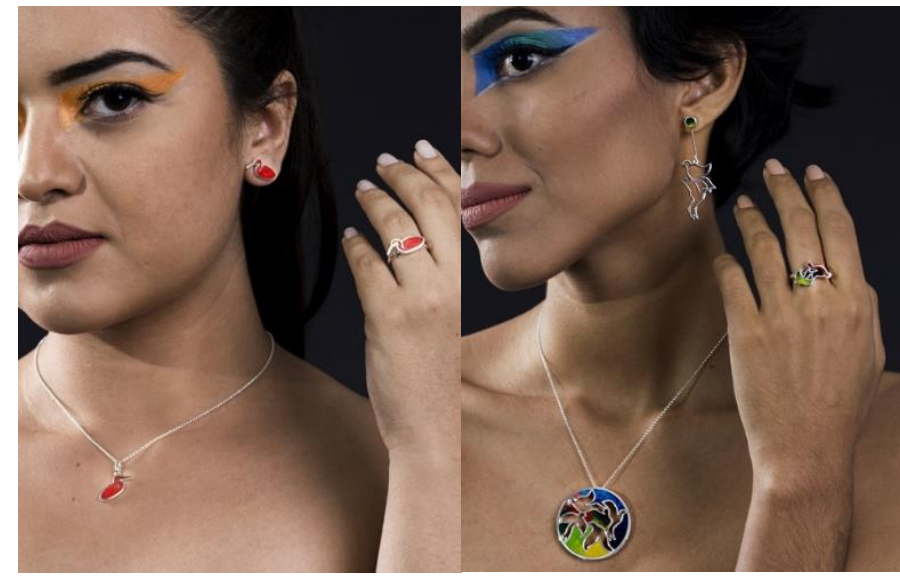

Fonte: Acervo do Autor (2017)

Para a abertura da exposição foi convidado o grupo de Pássaro Junino Uirapuru, que realizou uma pequena, mas muito interessante encenação e a amostra de um pouco dessa cultura popular para as pessoas ali presente. Isso contribui sensivelmente para o fortalecimento da ideia de valorização da cultura popular e, em especial, desse teatro, pois foi claro o encantamento dos presentes naquele espaço, levando-lhes o conhecimento do que seria esse teatro popular além das joias. Na figura 7 observamos alguns membros do grupo Uirapuru, juntamente com seus figurinos.

\footnotetext{
${ }^{4}$ Antigo presídio de Belém que foi reformado para ser um Polo Joalheiro do Pará.
} 
Figura 7 - Grupo Junino Uirapuru

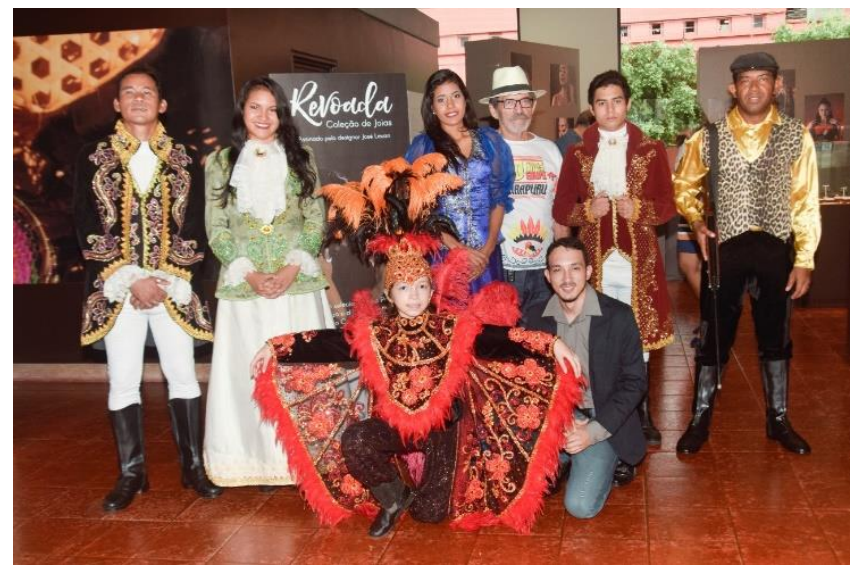

Fonte: Autor (2017)

O espaço que recebeu a exposição contou com quase todas as peças da coleção, menos as que foram projetadas em ouro, por conta da inviabilidade financeira dessas peças relacionado ao recurso disponível para fabricação da coleção. Na figura 7 observa-se o espaço da exposição que ficou em um período de duas semanas.

Figura 8 - Exposição Coleção Revoada

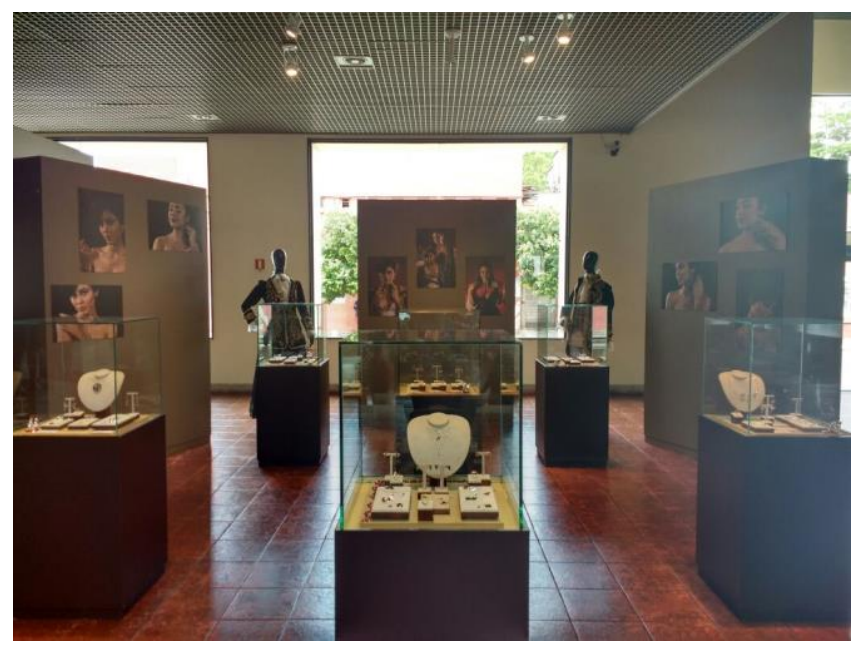

Fonte: Autor (2017)

\section{Conclusão}

A ligação do autor, desde a infância, com a cultura dos pássaros juninos foi um grande motivador para realizar este projeto, visando sempre a vertente pretendida de formação, a área de design de joias, pois já é onde o pesquisador trabalha atualmente e que facilitou na execução do trabalho. No decorrer da pesquisa observou-se que as joias trazem sempre conceitos e um pouco de história que está presente dentre suas formas e cores sendo a joia relevante para expressão da sociedade.

Este trabalho comprova que a cultura inserida em produtos de Design compreende os 
atributos estéticos do objeto, sendo um fator decisivo e atrativo para os consumidores, se tornando até um diferencial diante de outros produtos e é essa característica que faz as joias paraenses terem destaque nacional e internacional, como ocorre com as Joias do Círio de Nazaré, coleções apresentadas em evento específico cultural na cidade de Belém do Pará, no Espaço São José Liberto, o que corrobora com este projeto.

Os Pássaros Juninos na atualidade, ao longo de sua existência, tiveram uma queda em sua visibilidade e mudanças nas temáticas abordadas, já que anteriormente o foco principal das apresentações era o pássaro em si, onde havia a sua caçada, a sua morte e a sua ressurreição, mas, em um acordo entre guardiões, houve a mudança em relação a este personagem central, fazendo com que não houvesse mais a sua morte e em alguns grupos, o animal nem chegaria a ser ferido.

Este novo modo de trabalhar o enredo foi adotado para relacionar as questões ambientais quanto a extinção da Fauna e Flora, indicando que o fato desta mudança tenha descentralizado o pássaro das histórias, o que não tornou as apresentações deste teatro popular menos belas, mas reforçou a importância dessa visão ambiental. Sendo este um dos caminhos definidos e apresentados na coleção deste projeto em suas linhas.

Com a execução da exposição, permitiu-se com que houvesse um feedback real dos consumidores e visitantes, comprovando que a cultura dos pássaros juninos ainda é algo desconhecido por grande parte da sociedade de Belém e as pessoas que já conheciam, falaram o quanto é importante realmente em trazer esta visibilidade a esta cultura e outros elogios, mas já destinados as peças.

As pessoas que não conheciam esta cultura popular, quando adentravam na exposição, ficavam maravilhadas com os figurinos utilizados pelos brincantes e ansiosos por conhecer mais sobre a cultura, comprovando realmente que a joia pode levar consigo e transmitir valores prédefinidos e atingindo o objetivo principal de valorização e representação da cultura dos pássaros juninos, comprovando que através da função estética e simbólica dos produtos há a viabilidade da divulgação de qualquer temática abordada, servindo como difusor da cultura deste teatro popular genuinamente belenense.

Esta pesquisa abre outras possibilidades de realização de projetos futuros, pois ao longo deste trabalho percebeu-se uma relação direta de alguns personagens ligados à religião da umbanda, especificamente através da personagem feiticeira e de seus ritos. Há hipótese de que a própria origem da cultura dos pássaros possua ligação com a umbanda, mas se faz necessário um aprofundamento sobre o tema para saber se há realmente esta relação. Outra possibilidade é a inserção dos conceitos ambientais a partir do uso de materiais alternativos na coleção, pois os pássaros trabalham com esta visão.

\section{Referências}

ABRAHIM, L. A Técnica da Incrustação Paraense: Ilustrada através da Coleção de Joias “Mangueirosas". Belém, 2007. 139 p. Originalmente apresentado como Trabalho de Conclusão de Curso, Universidade do Estado do Pará, 2007.

ASSOCIAÇÃO SÃO JOSÉ LIBERTO. Catálogo da Pará Expojóia - Amazônia Design. Belém-PA, 2004. BAXTER, M. Projeto de Produto: Guia Prático para o design de novos produtos. 3a ed. São Paulo: Blucher, 2011 
CHAGAS, C. F. O imaginário na joalheria paraense: joias do polo joalheiro. Belém, 2012. 105 p. Originalmente apresentado como dissertação de mestrado, Universidade Federal do Pará, 2012.

CHARONE, O. Uma escuta sobre as canções do espetáculo: 0 sofrimento de Camila, do Grupo Melodrama Fantasia Tem-Tem de Belém do Pará. Revista Ensaio Geral, Belém, v. 2, n. 3, jan-jul. 2010.

COELHO, L. A. L. Conceito-chave em Design. Rio de Janeiro: Ed. PUC-Rio, 2008.

GOLA, E. A Joia: história e design. São Paulo: Editora Senac São Paulo, 2008.

HESKETT, J. Design. 1a ed. São Paulo: Ática, 2008.

LOUREIRO, J. de J. P. Uma Ontologia Fragmentária sobre o Teatro de Pássaros do Pará. In: OLIVEIRA, Elaine, et al. Escola de Pássaros: Reflexões sobre o Teatro Popular do Pará. Belém: Fundação Cultural do Estado do Pará, 2015.

PAZMINO, A. V. Como se cria: 40 métodos para design de produtos. São Paulo: Blucher, 2015.

PINTO, R. G. $O$ estado da arte do setor de gemas e joias no município de Belém-PA. Belém, 2012. 105 p. Originalmente apresentado como Dissertação de Mestrado, Universidade Federal do Pará, 2012.

PINTO, R. G. Joia Paraense: Pesquisas Desenvolvidas pelo Curso de Design do Centro de Ciências Naturais e Tecnologia da Universidade do Estado do Pará - UEPA. In: NEVES, Rosa, et al. Joias do Pará: Design, Experimentações e Inovação tecnológica nos modos de fazer. Belém: Paka Tatu, 2011.

RAMOS, A. V. O design de aparência de atores e a comunicação em cena. São Paulo: Editora Senac São Paulo, 2013.

REFKALEFSKY, M. Pássaros... Bordando Sonhos: Função Dramática do Figurino no Teatro dos Pássaros em Belém do Pará. Belém: Instituto de Arte do Pará, 2001. (Caderno IAP).

SANTOS, R. Joias: fundamentos, processos e técnicas. 1a ed. Rio de Janeiro: Senac Nacional, 2013.

SENAI. Senai Mix Design Inspirações e Tendências - Direções Criativas Outono-Inverno 2017. São Paulo-SP, 2016.

SENAI. Senai Mix Design Joias Folheadas, Bijuterias, Gemas e Joias - Outono-Inverno 2017. São Paulo-SP, 2016.

STOREY, J. Teoria Cultural e Cultura Popular: uma introdução. Tradução de Pedro Barros. São Paulo: Edições Sesc São Paulo, 2015.

WONG, W. Princípios de Forma e Desenho. São Paulo: Martins Fontes, 2001. 